\title{
Assessing the risks of intervention: immobilization, radio-collaring and vaccination of African wild dogs
}

\author{
Rosie Woodroffe
}

\begin{abstract}
Controversy has surrounded the role of intervention in studies of African wild dogs Lycaon pictus. Following the death or disappearance of all wild dogs under study in the Serengeti ecosystem, it was suggested that immobilization, radio-collaring or administration of rabies vaccines might have caused high mortality by compromising wild dogs' immune response to rabies virus. Planning future management and research on wild dogs and other species demands an assessment of the risks associated with such intervention. This paper critically reviews the available evidence and concludes that it is extremely unlikely that intervention contributed to the extinction of wild dogs in the Serengeti ecosystem. A more likely scenario is that vaccination failed to protect wild dogs exposed to rabies virus. Radio-collaring is an important component
\end{abstract}

\section{Introduction}

The African wild dog Lycaon pictus is one of the world's most endangered predators. Formerly widespread throughout sub-Saharan Africa, today between 3000 and 5500 wild dogs remain in the wild, with many populations still declining (Fanshawe et al., 1997). The species' extreme rarity is illustrated by the fact that Africa's elephants now out-number its wild dogs by around a hundred to one (Said et al., 1995; Fanshawe et al., 1997).

Efforts to conserve wild dogs have been driven by conservation-orientated research. Field studies have identified persecution, accidental killing, infectious disease and competition with larger predators as the major threats to wild dog populations, and have thus directed conservation recommendations (Creel \& Creel, 1998; Woodroffe \& Ginsberg, 1999a). As wild dogs live at low densities, and range very widely, all such studies have used radio-telemetry to locate marked animals; immobilization of wild dogs to fit radio-collars has therefore been a crucial component of these projects.

Rosie Woodrotfe IUCN/SSC Canid Specialist Group, Department of Biological Sciences, University of Warwick, Coventry, CV4 7AL, UK. E-mail: r.b.woodroffe@warwick.ac.uk. Present address: Department of Wildlife, Fish \& Conservation Biology, University of California, One Shields Avenue, Davis, CA 95616 USA.

Revised manuscript accepted for publication 8 December 2000 of wild dog research; hence, the benefits of immobilization appear to outweigh the risks, as long as (i) research is orientated towards wild dog conservation, (ii) radiocollaring is followed up by efficient monitoring, (iii) the number of animals immobilized is kept to the minimum necessary to maintain scientific rigour, and (iv) full data on disease and genetics are collected from all immobilized animals. By contrast, rabies vaccination currently seems to confer few benefits, at least when a single dose of vaccine is given. Further research, on captive animals, is in progress to establish more effective protocols, and to assess the role that vaccination might play in future management of wild dog populations.

Keywords conservation, Lycaon pictus, rabies, stress, wildlife disease.

Immobilization of animals (primarily for radio-collaring) has also been vital in assessing disease risks (Alexander et al., 1993a; Gascoyne et al., 1993a; van Heerden et al., 1995; Creel et al., 1997; Laurenson et al., 1997), and in studies of conservation genetics (Girman \& Wayne, 1997).

Occasionally, intervention has extended beyond immobilization and radio-collaring. Three different groups of researchers have identified acute risks of rabies infection, and therefore administered rabies vaccines to animals being studied in two populations (Gascoyne et al., 1993a; Kat et al., 1995; Hofmeyr et al., 2000).

Immobilization, radio-collaring and vaccination of wild dogs (collectively termed 'handling') has been well-intentioned; however, concern has been raised about its advisability. Following the death and disappearance of wild dogs under study in the Serengeti ecosystem (Gascoyne et al., 1993a; Kat et al., 1995), it was suggested that handling of study animals might have caused high mortality, contributing to local extinction (Burrows, 1992; Burrows et al., 1994). A hypothesis which I shall term the handling-immunosuppression hypothesis - was put forward, proposing that such intervention, perhaps in combination with some form of social stress, compromised wild dogs' immune systems leading to the reactivation of quiescent rabies infections (Burrows, 1992; Burrows et al., 1994). Burrows and his 
coauthors argued that such reactivation would be followed by transmission of the virus to pack members that had not been handled, leading to rapid death of the whole pack.

This hypothesis has been discussed at length in both the scientific and popular literature (e.g. Heinsohn, 1992; Morell, 1995; Dye, 1996; Burrows, 1998), and, in some range states, has made government departments reluctant to grant permission for further research involving intervention. It is vital that future plans for wild dog conservation be based upon a realistic assessment of the costs and benefits of intervention. To this end, this paper discusses the handling-immunosuppression hypothesis, using the discussion to evaluate the roles that immobilization, radio-collaring and vaccination of free-ranging wild dogs may play in future plans to conserve this and other endangered species.

\section{Recent history of wild dogs in the Serengeti ecosystem}

The wild dog population occupying the Serengeti ecosystem was the subject of two research projects, one based in the Serengeti National Park (in Tanzania), and one outside the Masai Mara National Reserve in neighbouring Kenya (Fuller \& Kat, 1993; Burrows, 1995). A total of 15 packs were identified over the period 1986$1991 ; 12$ of these contained animals which had been immobilized and fitted with radio-collars, and were therefore classified as study packs (Table 1). Eight packs contained animals which had been vaccinated against rabies, either while immobilized or by dart. In all cases, inactivated rabies vaccines were used: Madivak (Hoechst, Germany) in Tanzania, and Imrab (Rhône-Merieux, Fort Dodge, USA) in Kenya (Gascoyne et al., 1993b; Kat et al., 1995).

Members of five of the 15 packs were seen dead or dying, apparently from disease: rabies was confirmed from three of these packs (Table 1). Two of the animals found to have died from rabies had previously been vaccinated against the disease (Table 1). Unfortunately, the limited monitoring of the population following vaccination means that the fates of most individuals remains unknown.

By December 1991, all of the remaining packs had disappeared (Table 1). Two unmonitored packs may also have disappeared (Kat et al., 1995). These packs were reported by local people from an area to the north of the Masai Mara study site, but were never sighted by researchers (P. Kat, pers. comm.). They were last sighted in April-May 1991 (P. Kat, pers. comm.). Between 1991 and 1998, only vagrant animals and single-sex dispersing groups have been recorded from the Serengeti ecosystem (J. Gunn, unpublished data; Burrows et al., 1994).

\section{Were pack deaths associated with intervention?}

Burrows et al. (1994, 1995) sought associations between interventions and mortality by comparing (i) handled with unhandled packs, (ii) time periods when handling was common or rare, and (iii) handled and unhandled individuals. Most such analyses investigated the effects of all forms of 'handling' together, as well as treating immobilization, vaccination and radio-collaring separately.

\section{Was mortality confined to packs which were handled?}

Burrows et al. (1994, 1995) argued that study packs disappeared while non-study packs, which were never handled, survived. The majority of the packs identified were subsequently radio-collared; minimal data are available on the few packs that were not handled. One, the Moru Track pack, was last reported in December 1991 (Table 1; Burrows et al., 1994), but previous sightings were intermittent, suggesting that the pack might not have been resident in the Serengeti study area. Two further packs apparently disappeared from an area north of the Mara study area in 1991 (see above), but, again, data are extremely poor. Packs were sighted to the east of Serengeti National Park in November 1990 and in early 1992 (S. Cleaveland*, pers. comm.; Burrows, 1993), but it is not known whether these sightings represent the same pack. Mortality was certainly not confined to vaccinated packs: five study packs that disappeared in the period 1986-90 contained no vaccinated members (Table 1 ).

Burrows et al. (1994) argued that a wild dog population remained, undetected, outside the Tanzanian study area after the study packs disappeared, because the number of unknown wild dogs entering the Serengeti study area annually was no lower after the local extinction than in the previous 6 years. This assertion is difficult to evaluate, however. Wild dogs are known to disperse over hundreds of kilometres (Fuller et al., 1992b; Scheepers \& Venzke, 1995), and may be sighted in areas - even countries - with no resident populations (Fanshawe et al., 1997). Thus, whereas records of dispersing animals in the former study sites show that a breeding population existed elsewhere, they do not necessarily indicate that this population inhabited areas immediately adjoining the study areas. The failure of any packs to re-establish a breeding population in

${ }^{*}$ formerly S. Gascoyne 


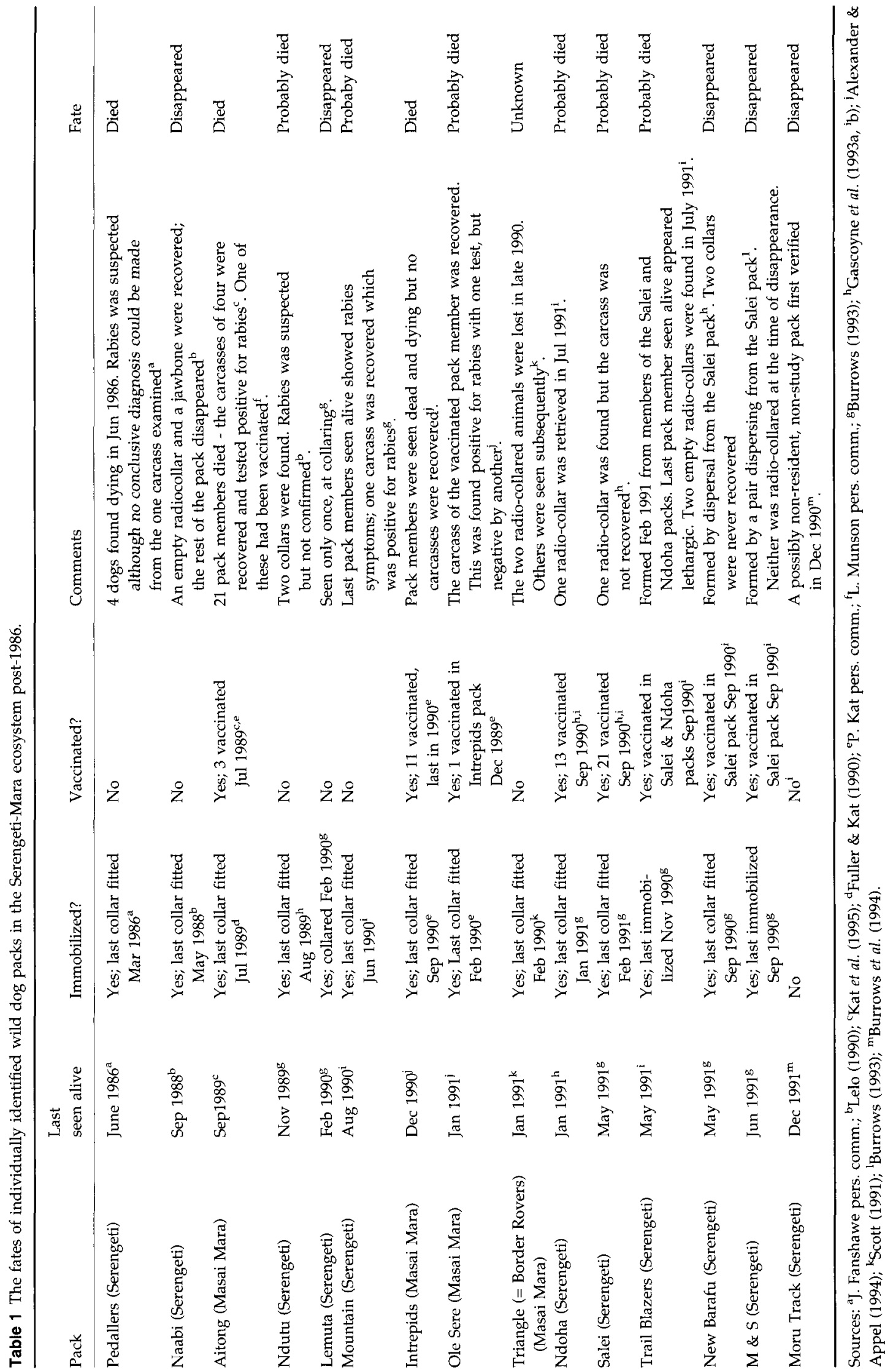


Serengeti - in contrast to the rapid recolonization of suitable habitat in Zimbabwe (A. Pole, pers. comm.) argues against the persistence of a substantial population in adjoining areas.

In summary, mortality may not have been confined to handled packs: non-study packs may have disappeared around the same time as the study packs. However, the data are too poor to give a confident assessment.

Was mortality lower in unhandled animals, or at times when intervention was rare?

Burrows et al. (1994) suggested that wild dog mortality in Serengeti National Park was associated with intervention. Longevity of both packs and individual adults was shorter in 1985-91, when handling occurred routinely, than in 1970-77 when little handling took place (Burrows et al., 1994). Furthermore, within the 1985-91 study period, individuals that were handled suffered higher mortality than those that were not. Animals which were vaccinated by dart survived for shorter periods than did those which were only radio-collared, and animals radio-collared after they had joined a new pack survived for shorter periods than did those collared prior to dispersal (Burrows et al., 1994).

These data indicate an association between mortality and intervention - especially vaccination - in the Serengeti National Park study area. However, they must be evaluated with caution because the associations are not necessarily evidence for a causal relationship. A period of high mortality occurred during 199091, during which many of the individual and wholepack deaths were recorded. Thirty-four of the 52 wild dogs that were handled - including all those vaccinated - were handled in 1990, immediately prior to this high-mortality period (Gascoyne et al., 1993a, b). In contrast, most study animals were left unhandled in 1985-89, even though the majority of radio-collars (18/ 22) were fitted during this period (Burrows et al., 1994). Given the timing of events, associations between handling in general, and vaccination in particular, would be expected whether or not the high mortality observed in 1990-91 was caused by the handling. Specifically, the same associations would occur if some unrelated event - such as a disease epidemic in another species - triggered the die-off among wild dogs (Ginsberg, 1996).

Comparisons of the fates of immobilized and unhandled wild dogs revealed no associations between immobilization and mortality in four other wild dog populations in East and southern Africa (Ginsberg et al., 1995). Note that no vaccination took place in these four populations. Despite claims of both a positive (Burrows et al., 1995; East, 1996) or no association (Ginsberg et al.,
1995; Ginsberg, 1996) between handling and mortality in the Masai Mara part of the Serengeti population, data have not been made available to permit a full analysis (Woodroffe, 1997).

Burrows et al.'s (1994) analyses do indicate a statistical association between intervention and mortality in Serengeti. After considering a suite of other ecological factors, Burrows et al. (1994, 1995) concluded that the handling-immunosuppression hypothesis was the most likely explanation for the associations observed. Their analyses cannot determine whether the observed relationships are causal - nevertheless, they do give cause for concern, indicating that the handlingimmunosuppression hypothesis merits detailed consideration.

\section{The handling-immunosuppression hypothesis}

Burrows' hypothesis concerns the effect of handling on immune responses to rabies infection (Burrows, 1992). The hypothesis would be supported by evidence that (i) rabies was the primary cause of whole-pack deaths, (ii) handled animals could have been harbouring nonfatal rabies infection, and (iii) immobilization, radiocollaring or vaccination had the capacity to trigger reactivation of this infection. In this section, I discuss these issues in turn.

\section{Did rabies cause all the pack deaths?}

While rabies was clearly involved in the deaths of some wild dog packs in the Serengeti ecosystem (Table 1), several authors have suggested that rabies alone did not cause the population extinction, suggesting instead that canine distemper virus (CDV) might have been involved (Macdonald et al., 1992; Alexander \& Appel, 1994). This hypothesis stems primarily from the view that rabies would be unlikely to cause such high mortality in a vaccinated population (Macdonald et al., 1992): eight packs, containing at least 48 rabies-vaccinated animals, disappeared in the die-off (Table 1).

Evidence of a role for CDV is entirely circumstantial: the only carcasses available for testing (from the Aitong pack) were found negative (L. Munson, pers. comm.). However, CDV has caused whole-pack deaths elsewhere (Alexander et al., 1996), and Alexander \& Appel (1994) documented a CDV epidemic in local domestic dogs in 1990-91, suggesting that wild dogs could have contacted infection around the time of the Serengeti dieoff. None of the wild dogs sampled in either study before the die-off were found to be seropositive for CDV (M.K. Laurenson, pers. comm.; Alexander \& Appel, 1994), suggesting that none had been exposed and, 
hence, that the population would have been susceptible to infection.

In the absence of any confirmed diagnoses of CDV infection, evidence for the involvement of a pathogen other than rabies depends primarily upon the probability that rabies vaccination could fail to provide protection on such a large scale. The available evidence suggests that such vaccine failure is not unlikely. Rabiesvaccinated wild dogs are known to have come into contact with rabies virus in two populations founded by reintroduction, as well as in the Serengeti ecosystem; some vaccinated animals died of rabies in all cases (Table 2). Similar reports of vaccine failures are occasionally reported from domestic dogs (Clark et al., 1981; Bourhy et al., 1988; Eng et al., 1994).

How might vaccination have failed? The vaccines used in Serengeti were licensed to provide three years' protection for domestic dogs, following a single dose (S. Cleaveland, pers. comm.; Rhône-Merieux, pers. comm.), but their effectiveness in wild dogs was (and remains) largely unknown. Responses to vaccination are frequently assessed by measuring serum antibody levels - although cell-mediated immunity plays an important role in the body's defences against rabies, and it is not known how antibody levels correspond with immunity to rabies infection in wild dogs. Of three wild dogs that had had blood samples taken before and after vaccination, at least one failed to develop a high antibody titre (P. Kat, pers. comm.; Gascoyne et al., 1993a). A single dose of another inactivated rabies vaccine, Dohyrab (Solvay Duphar), administered to 25 captive wild dogs, generated no seropositives (Visee, 1996). New data indicate that two or three doses might be more successful in generating a protective immune response in wild dogs (G.R. Thomson, pers. comm.), although repeated vaccination of three captive wild dogs failed to prevent rabies antibody titres from falling (Hofmeyr et al., 2000), and annual vaccination failed to protect wild dogs from rabies during a reintroduction attempt in Namibia (Table 2).

It is quite possible that wild dogs vaccinated in the Serengeti ecosystem remained susceptible to rabies infection, especially because they were given only single doses of vaccine. With no direct evidence of a role for $\mathrm{CDV}$, rabies remains the most likely cause of their disappearance.

\section{Could the handled wild dogs have been harbouring rabies virus?}

The handling-immunosuppression hypothesis proposes that intervention reactivated quiescent rabies infection in handled animals (Burrows, 1992). Such infection might then be transmitted to other pack members, even if they had not themselves been handled. To explain whole-pack deaths, then, the hypothesis assumes that a high proportion of handled wild dogs were harbouring quiescent rabies infection.

There are limited data to suggest that wild dogs immobilized in Serengeti National Park had contacted rabies virus in the past: three (of 12) showed low titres of rabies serum neutralizing antibodies (Gascoyne et al., $1993 a, b)$. None of 18 wild dogs sampled in the Mara area showed evidence of exposure (Alexander et al., 1993b). The assay used was not validated for use on wild dogs and so it may simply have detected non-specific serum antibodies, as can occur in domestic dogs (Fekadu, 1991a). Nevertheless, the possibility remains that some of the wild dogs sampled had previously been exposed to rabies infection.

Exposure to rabies virus can lead to the maintenance of quiescent infection in two ways. First, domestic dogs may occasionally recover from clinical rabies infection, yet continue to excrete virus as healthy seropositive 'carriers' (Fekadu, 1991b). This condition is extremely rare, having been documented only in a single strain of rabies from Ethiopia (Fekadu, 1972; Fekadu et al., 1981). There, less than 0.5 per cent of domestic dogs are carriers (Fekadu, 1972); no carriers have been detected elsewhere, despite large-scale screening in rabiesendemic areas (Bell et al., 1971; Botros et al., 1979; Ratanarapee et al., 1982). Seropositivity is more usually evidence of aborted infection, where a successful immune response is mounted against infection which never reaches the central nervous system (Fekadu et al, 1982; Fekadu, 1991b; Fishbein \& Robinson, 1993); such animals no longer carry the virus and cannot be infectious. The carrier state has not been documented in wild dogs, and there is no reason to expect it to occur more commonly than in domestic dogs.

Quiescent rabies infection might also occur through latent infection. In such cases, the virus remains at or near the infection site, without provoking a humoral immune response (Fekadu, 1991b; Fishbein \& Robinson, 1993). In humans, latent infection has lasted as long as 6 years before reactivation (Smith et al., 1991). While latent infection is undetectable by clinical means (Fishbein \& Robinson, 1993), the presence of seropositive animals in the Serengeti wild dog population suggests that packs might have been exposed to rabies virus. This raises the possibility that seronegative pack members might be sustaining latent infection. Latent infection appears to be uncommon in domestic dogs (Fekadu et al., 1982) and there is no reason to suppose that it might be more common in wild dogs than in domestic dogs.

Both the carrier state and latent infection are rare occurrences in domestic dogs. It can be expected that 


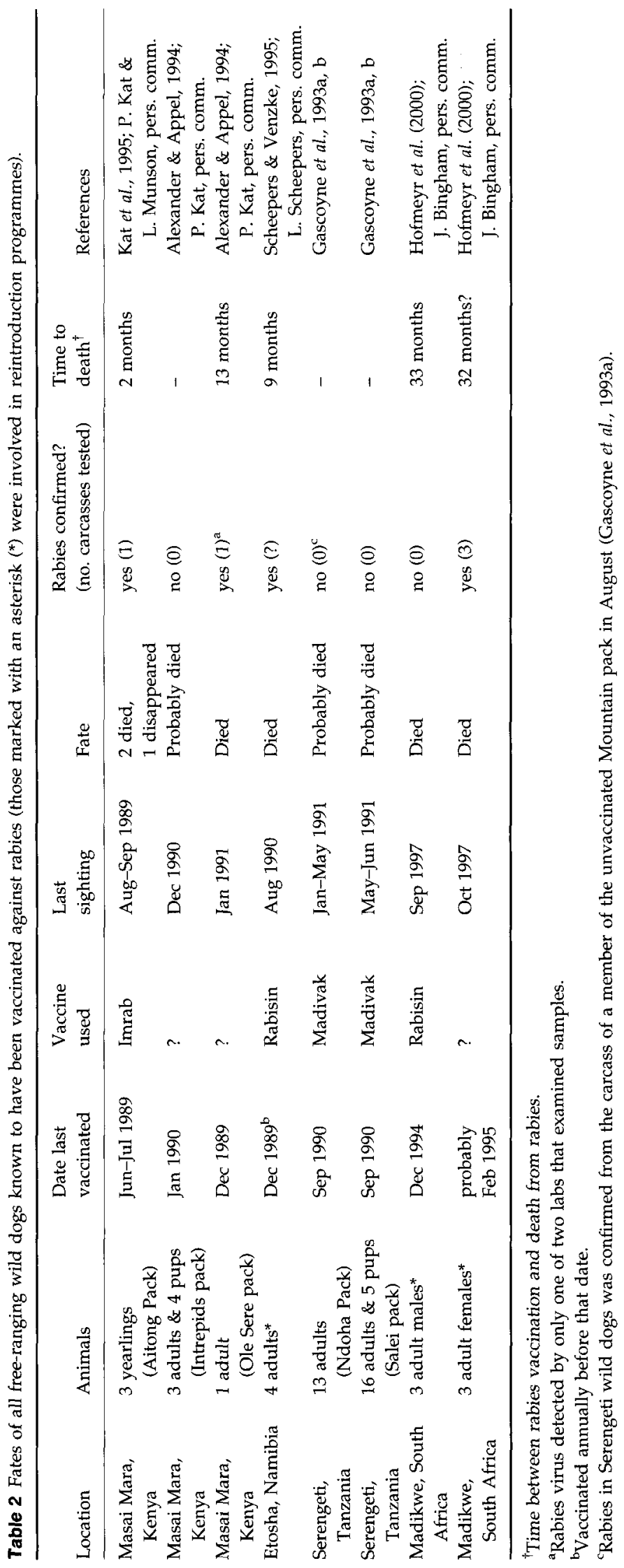


such states would be most likely to be found in populations suffering endemic or epidemic rabies infection, which would also be characterized by sustained or episodic high mortality from rabies infection. Rabies outbreaks recorded in wild dogs have caused close to 100 per cent mortality in packs known to have been exposed (Kat et al., 1995; Scheepers \& Venzke, 1995; Hofmeyr et al., 2000). No such high mortality was documented in the Serengeti wild dog population (prior to the 1990-91 die-off), therefore the occurrence of quiescent rabies infection in Serengeti wild dogs would be surprising.

In summary, the serological data might provide evidence that Serengeti wild dogs had had prior contact with rabies virus. However, rabies is almost invariably fatal in domestic dogs (Fekadu, 1991a) and, where documented, in wild dogs. There is no evidence to suppose that quiescent infection - in the form of either a seropositive carrier state, or a seronegative latent state might be more common in African wild dogs than in domestic dogs. Thus it appears very unlikely that a high proportion of wild dogs handled in the Serengeti ecosystem were sustaining quiescent rabies infection.

\section{Could handling wild dogs reactivate quiescent rabies infection?}

Assuming that wild dogs were indeed harbouring rabies virus, Burrows et al. (1994, 1995) proposed three mechanisms by which intervention might have reactivated quiescent infection. Immobilization might have triggered reactivation, either through the stress it imposes, or by some immunosuppressive effect of the drugs used. Alternatively, the vaccines delivered might have acted as immunosuppressants. Such effects might be exacerbated by social stress (Burrows et al., 1994). I shall discuss the possibilities in order.

\section{Immobilization stress}

Immobilization stress is believed to result from the disorientation caused by the process of anaesthesia. Immobilization does impose acute stress on wild dogs, although this appears no more severe than in other large carnivores (de Villiers et al., 1995). Repeated, non-invasive sampling of faecal corticosteroids in wild dogs before and after immobilization and radio-collaring show that such handling does not involve chronic stress (Creel et al., 1996b).

Limited experimental evidence suggests that chronic stress might reactivate latent rabies infection: some guinea pigs and raccoons that had survived challenge with rabies virus developed clinical symptoms and died when subsequently exposed to chronic stressors (Soave et al., 1961; Soave, 1964; McLean, 1975). These experi- ments must be interpreted with caution because they included no control animals not exposed to the stressors and could not therefore distinguish apparent reactivation from simple prolonged incubation.

The only evidence for an effect of acute (rather than chronic) stress on reactivation is anecdotal: the stress of parturition was blamed for the death, from rabies, of a domestic dog that had been an infectious carrier of rabies for 10 months (Fekadu, 1991b).

Where stressors have been implicated in rabies reactivation in the laboratory, clinical symptoms and death have occurred rapidly, usually on a timescale shorter than the typical incubation period (Soave et al., 1961; Soave, 1964; McLean, 1975). In contrast, immobilized wild dogs survived for long periods: 12 wild dogs collared in Serengeti National Park survived 17 months (510 days) on average, and six collared in the Mara area survived 66-111 days (Burrows et al., 1994, 1995). For comparison, the recorded incubation period for rabies in wild dogs is $8-42$ days, and natural adult mortality in wild dog populations is c. 25-35 per cent per year (Fuller et al., 1992a; Kat et al., 1995; Hofmeyr et al., 2000).

Burrows et al. (1994) suggested that social stressors might exacerbate any effects of handling because longevity was especially short for wild dogs collared after they had formed new packs. No data are available on the stresses associated with pack formation, although dominant status is known to elevate stress hormones in wild dogs (Creel et al., 1996a). Since social conditions may lead to chronic stress, whereas immobilization imposes only acute stress, it seems likely that social environment alone might have more deleterious effects.

In conclusion, it seems unlikely that immobilization stress reactivated rabies infection in wild dogs in the Serengeti ecosystem. The limited data available suggest that if chronic stress can reactivate rabies infection, this occurs relatively rapidly. By contrast, the pattern observed in wild dogs involved death or disappearance several months after the imposition of a mild acute stress.

\section{Immobilization agents}

General anaesthesia is known to suppress immune function in both humans and domestic dogs (Felsburg et al., 1986; Fescharek et al., 1994). Wild dogs in the Serengeti ecosystem were immobilized with telazol (A.H. Robins Co, Richmond, VA), xylazine (Rompun, Bayer) and ketamine (Vetalar, Parke Davis) (Alexander et al., 1993b; Gascoyne et al., 1993b).

Two pieces of evidence argue against an effect of immobilization agents on rabies infection in wild dogs in the Serengeti ecosystem. Firstly, in domestic dogs immune function is restored within 1-4 days of anaes- 
thesia (Felsburg et al., 1986), yet wild dogs died or disappeared several months after immobilization (Burrows et al., 1994, 1995). Secondly, Burrows et al. (1994) reported the shortest longevity for dart-vaccinated wild dogs - animals which were never immobilized.

\section{Vaccination}

The effect of rabies vaccines upon the immune response of wild dogs to rabies would depend on whether the vaccines were administered before or after exposure. Post-exposure vaccination is a routine component of rabies treatment and could be expected to enhance, rather than reduce, the chances of wild dogs surviving latent infections (Fishbein \& Robinson, 1993). Vaccination immediately before exposure may, however, compromise immune responses to rabies challenge, leading to shortened incubation periods (termed 'early death' in rabies-vaccinated domestic dogs, Clark et al., 1981). As wild dogs in Serengeti National Park survived 7 months (210 days), on average, following vaccination (Burrows et al., 1994), and rabies incubation lasts 8-42 days (Kat et al., 1995; Hofmeyr et al., 2000), it seems highly unlikely than any animals succumbed to 'early death' as a result of rabies vaccination.

\section{Do the data support the handling-immunosuppression hypothesis?}

These data suggest that the handling-immunosuppression hypothesis is not a plausible explanation for the disappearance of wild dogs under study in the Serengeti ecosystem. Rabies remains the most likely cause of their disappearance. It is highly unlikely that a significant proportion of the handled animals was sustaining nonlethal rabies infection. Even if this were the case, neither immobilization nor vaccination would be likely to reactivate the infection, particularly on the timescale observed.

While the handling-immunosuppression hypothesis may not withstand scrutiny, statistical associations between handling and longevity in Serengeti National Park (Burrows et al., 1994) could still give cause for concern. However, as explained above, the same associations would be generated by a period of high mortality occurring in 1990-91, independent of any effects of intervention. As outlined above, such mortality was most likely caused by a rabies outbreak.

A highly pathogenic infection such as rabies is likely to 'spill over' from other, more common, species such as jackals or bat-eared foxes (Woodroffe, 1999). No die-off was recorded among small canids in the Serengeti National Park study site during 1990-91, but these species were not monitored at that time.
These findings suggest an alternative scenario, in which mass mortality of wild dogs in 1990-91 was caused by an outbreak of a disease against which rabies vaccination failed to provide protection (perhaps because the protocol used was ineffective, perhaps because the pathogen was not rabies).

\section{Conclusions - the future role of interventions}

The data presented above suggest that handling is not likely to have contributed to the demise of wild dogs in the Serengeti ecosystem. Nevertheless, there is a small probability that such interventions might have adverse effects. In this context, it is important to evaluate their future role in wild dog conservation.

\section{Immobilization and radio-collaring}

As discussed above, research on wild dogs over the last decade has revolutionized approaches to their conservation, revealing the unusual threats that they face (Creel \& Creel, 1998; Woodroffe \& Ginsberg, 1999a), and indicating the likely success of various approaches to their conservation (Woodroffe \& Ginsberg, 1999b). Radio-telemetry has played a vital role in such research; without this tool, it would be impossible to monitor such a wide-ranging species in dense and often inhospitable terrain. In addition, samples collected from immobilized wild dogs have been crucial in evaluating the importance of threats such as disease and inbreeding depression (Woodroffe \& Ginsberg, 1999a). Field studies have answered many questions needed to plan future wild dog conservation, but further research is urgently needed to assess the efficacy of conservation measures, to refine assessments of the various threats, and to identify new threats as they emerge (Ginsberg \& Woodroffe, 1997).

The risks associated with immobilization and radiocollaring are questionable in Serengeti, and undetectable elsewhere (Ginsberg et al., 1995; Creel et al., 1996b). The benefits of these interventions therefore appear to outweigh the costs at present. To minimize the risks, however, wild dogs should only be immobilized or radio-collared when (i) there is a clear conservation benefit to the study, in terms of research and/or monitoring, (ii) the necessary data cannot be obtained by non-invasive methods (e.g. from faeces, Creel et al., 1996b; Kohn \& Wayne, 1997), (iii) the number of animals immobilized is kept to the minimum necessary to maintain scientific rigour, (iv) funding, manpower and infrastructure ensure that radio-collaring can be followed up by regular monitoring, (v) analyses similar to those presented in Ginsberg et al. (1995) are carried 
out periodically as part of an ongoing process of monitoring the risks associated with such handling, and (vi) maximum data are gathered from any animal immobilized, including, especially, screening for disease and collection of genetic samples.

Should another die-off be witnessed by researchers, it is vital that every attempt is made to collect the field data needed to evaluate the causes. Any such data should be published in a full and open manner.

\section{Vaccination}

While rabies vaccination appears not to have caused deaths of wild dogs in the Serengeti ecosystem, it has certainly failed to protect free-ranging populations from rabies infection (Table 2). At present therefore rabies vaccination appears to have little value in protecting free-ranging wild dog populations. New research has been initiated, under the auspices of the IUCN Canid and Veterinary Specialist Groups, to determine whether a more reliable and effective rabies vaccination protocol can be established. This research is integrated with field studies to investigate whether direct vaccination of wild dogs can in any circumstances form a component of a sustainable strategy to protect African wild dogs from rabies.

CDV may also represent a major threat to some wild dog populations; however, CDV vaccination is not appropriate at present because inactivated vaccines are ineffective (Visee, 1996), and live vaccines may prove fatal (McCormick, 1983; van Heerden et al., 1989; Durchfeld et al., 1990). Newly developed subunit vaccines may be more effective, and safety trials on captive wild dogs should be considered as a first step in evaluating CDV vaccination as a component of disease management.

General concerns about the safety, effectiveness and sustainability of direct vaccination point to the need for a more ecological approach to disease control in endangered species, in which management may be targeted at threatened or reservoir hosts, or at contact between threatened and other host species (Woodroffe, 1999). Further research is urgently needed to inform the design of programmes in this emerging field.

\section{Acknowledgements}

Much of the information presented in this paper was collated during preparation of the IUCN Status Survey and Conservation Action Plan for the African Wild Dog (Woodroffe et al., 1997). I would like to thank Josh Ginsberg, Kathy Alexander, Marc Artois, Sarah Cleaveland, Scott Creel, Sarah Durant, John Fanshawe, Arthur King, Hans Kruuk, Karen Laurenson, David Macdonald, Gus Mills, Linda Munson, Gavin Thomson and two anonymous reviewers for comments on earlier drafts of this paper or relevant parts of the Action Plan. Two other researchers kindly provided extensive and helpful comments on Action Plan drafts but asked not to be named; nonetheless I am extremely grateful for their assistance.

\section{References}

Alexander, K. \& Appel, M. (1994) African wild dogs (Lycaon pictus) endangered by a canine distemper epizootic among domestic dogs near the Masai Mara National Reserve. Kenya. Journal of Wildlife Diseases, 30, 481-485.

Alexander, K.A., Conrad, P.A., Gardner, I.A., Parish, C., Appel, M., Levy, M.G., Lerche, N. \& Kat, P. (1993a) Serologic survey for selected microbial pathogens in African wild dogs (Lycaon pictus) and sympatric domestic dogs (Canis familiaris) in Masai Mara, Kenya. Journal of Zoo \& Wildlife Medicine, 24, 140-144.

Alexander, K.A., Kat, P.W., Munson, L.A., Kalake, A. \& Appel, M.J.G. (1996) Canine distemper-related mortality among wild dogs (Lycaon pictus) in Chobe National Park, Botswana. Journal of Zoo \& Wildlife Medicine, 27, 426-427.

Alexander, K.A., Smith, J.S., Macharia, M.J. \& King, A.A. (1993b) Rabies in the Masai Mara, Kenya: a preliminary report. Onderstepoort Journal of Veterinary Research, 60, 411-414.

Bell, J.F., Gonzalez, M.A., Diaz, A.M. \& Moore, G.J. (1971) Nonfatal rabies in dogs - experimental studies and results of a survey. American Journal of Veterinary Research, 32, 2049-2058.

Botros, B.A.M., Lewis, J.C. \& Kerkor, M. (1979) A study to evaluate non-fatal rabies in animals. Journal of Tropical Medicine \& Hygiene, 82, 137-141.

Bourhy, H., Lafon, M., Berthonneau, M.C., Renner, Y., Rollin, P.E. \& Sureau, P. (1988) Rabies in vaccinated dogs in Gabon. Veterinary Record, 122, 361-362.

Burrows, R. (1992) Rabies in wild dogs. Nature, 359, 277.

Burrows, R. (1993) Observations on the behaviour, ecology and conservation status of African wild dogs in SNP. In Serengeti Wildlife Research Centre Scientific Report 1990-92 (eds S. Huish and K. L. I. Campbell), pp. 53-59. Serengeti Wildlife Research Centre, Arusha, Tanzania.

Burrows, R. (1995) Demographic changes and social consequences in wild dogs 1964-92. In Serengeti II: Research, Management, and Conservation of an Ecosystem (eds A.R.E. Sinclair and P. Arcese), pp. 400-420. Chicago University Press, Chicago.

Burrows, R. (1998) What was the scientific basis of IUCN Canid Specialist Group's claim that handling of African wild dogs (Lycaon pictus) has no effect on their mortality, survival or longevity? IUCN/SSC Veterinary Specialist Group Newsletter, 15, 6-8.

Burrows, R., Hofer, H. \& East, M.L. (1994) Demography, extinction and intervention in a small population: the case of the Serengeti wild dogs. Proceedings of the Royal Society of London B, 256, 281-292.

Burrows, R., Hofer, H. \& East, M.L. (1995) Population dynamics, intervention and survival in African wild dogs (Lycaon pictus). Proceedings of the Royal Society of London B, 262, 235-245.

Clark, K.A., Kelly, V.P., Newman, E.C., Bilderback, W.R., Nettles, W.D. \& Rhodes, T.S. (1981) Rabies vaccination - field 
observations during epizootics in dogs. Modern Veterinary Practice, 62, 907-911.

Creel, S. \& Creel, N.M. (1998) Six ecological factors that may limit African wild dogs, Lycaon pictus. Animal Conservation, 1, $1-9$.

Creel, S., Creel, N.M. \& Monfort, S.L. (1996a) Social stress and dominance. Nature, 379, 212.

Creel, S., Creel, N.M. \& Monfort, S.L. (1996b) Radiocollaring and stress hormones in African wild dogs. Conservation Biology, 10, 1-6.

Creel, S., Creel, N.M., Munson, L., Sanderlin, D. \& Appel, M.J.G. (1997) Serosurvey for selected viral diseases and demography of African wild dogs in Tanzania. Journal of Wildlife Diseases, 33, 823-832.

Durchfeld, B., Baumgartner, W., Herbst, W. \& Brahm, R. (1990) Vaccine-associated canine distemper infection in a litter of African hunting dogs (Lycaon pictus). Zentralblatt für Veterinrmedizin B, 37, 203-212.

Dye, C. (1996) Serengeti wild dogs: what really happened? Trends in Ecology and Evolution, 11, 188-189.

East, M.L. (1996) Survivorship in African wild dogs. Conservation Biology, 10, 313.

Eng, T.R., Fishbein, D.B., Talamante, H.E., Fekadu, M., Chavez, G.F., Muro, F.J. \& Baer, G.M. (1994) Immunogenicity of rabies vaccines used during an urban epizootic of rabies in Mexico. Vaccine, 12, 1259-1264.

Fanshawe, J.H., Ginsberg, J.R., Sillero-Zubiri, C. \& Woodroffe, R. (1997) The status and distribution of remaining wild dog populations. In The African Wild Dog: Status Survey and Conservation Action Plan (eds R. Woodroffe, J.R. Ginsberg and D.W. Macdonald), pp. 11-57. IUCN, Gland.

Fekadu, M. (1972) Atypical rabies in dogs in Ethiopia. Ethiopian Medical Journal, 10, 79-86.

Fekadu, M. (1991a) Canine rabies. In The Natural History of Rabies (ed. G.M. Baer), pp. 367-378. CRC Press, Boca Raton.

Fekadu, M. (1991b) Latency and aborted rabies. In The Natural History of Rabies (ed. G.M. Baer), pp. 191-378. CRC Press, Boca Raton.

Fekadu, M., Chandler, F.W. \& Harrison, A.K. (1982) Pathogenesis of rabies in dogs inoculated with an Ethiopian rabies virus strain. Immunofluorescence, histologic and ultrastructural studies of the central nervous system. Archives of Virology, 71, 109-126.

Fekadu, M., Shaddock, J.H. \& Baer, G.M. (1981) Intermittent excretion of rabies virus in the saliva of a dog two and six months after it had recovered from experimental rabies. American Journal of Tropical Medicine and Hygiene, 30, 1113-1115.

Felsburg, P.J., Krawiec, D.R. \& Rubin, S.I. (1986) The effect of general anaesthesia on canine lymphocyte function. Veterinary Immunology \& Immunopathology, 13, 63-70.

Fescharek, R., Frank, V. \& Samuel, M.R. (1994) Do anaesthetic and surgical stress increase the risk of post-exposure rabies treatment failure? Vaccine, 12, 12-13.

Fishbein, D.B. \& Robinson, L.E. (1993) Rabies. New England Journal of Medicine, 329, 1632-1638.

Fuller, T.K. \& Kat, P.W. (1990) Movements, activity, and prey relationship of African wild dogs (Lycaon pictus) near Aitong, south-western Kenya. African Journal of Ecology, 28, 330-350.
Fuller, T.K. \& Kat, P.W. (1993) Hunting success of African wild dogs in South-Western Kenya. Journal of Mammalogy, 74, 464-467.

Fuller, T.K., Kat, P.W., Bulger, J.B., Maddock, A.H., Ginsberg, J.R., Burrows, R., McNutt, J.W. \& Mills, M.G.L. (1992a)

Population dynamics of African wild dogs. In Wildlife 2001: Populations (eds D.R. McCullough and H. Barrett). Elsevier Science Publishers, London.

Fuller, T.K., Mills, M.G.L., Borner, M., Laurenson, K. \& Kat, P.W. (1992b) Long distance dispersal by African wild dogs in East and South Africa. Journal of African Zoology, 106, 535-537. Gascoyne, S.C., King, A.A., Laurenson, M.K., Borner, M., Schildger, B. \& Barrat, J. (1993a) Aspects of rabies infection and control in the conservation of the African wild dog (Lycaon pictus) in the Serengeti region, Tanzania. Onderstepoort Journal of Veterinary Research, 60, 415-420.

Gascoyne, S.C., Laurenson, M.K., Lelo, S. \& Borner, M. (1993b) Rabies in African wild dogs (Lycaon pictus) in the Serengeti region, Tanzania. Journal of Wildlife Diseases, 29, 396-402.

Ginsberg, J. (1996) Survivorship in African wild dogs. Conservation Biology, 10, 313-315.

Ginsberg, J.R., Alexander, K.A., Creel, S., Kat, P.W., McNutt, J.W. \& Mills, M.G.L. (1995) Handling and survivorship of African wild dog (Lycaon pictus) in five ecosystems. Conservation Biology, 9, 665-674.

Ginsberg, J.R. \& Woodroffe, R. (1997) Research and monitoring: Information for wild dog conservation. In The African Wild Dog: Status Survey and Conservation Action Plan (eds R. Wood roffe, J.R. Ginsberg and D.W. Macdonald), pp. 112-117. IUCN, Gland.

Girman, D.J. \& Wayne, R.K. (1997) Genetic perspectives on wild dog conservation. In The African Wild Dog: Status Survey and Conservation Action Plan (eds R. Woodroffe, J.R. Ginsberg and D.W. Macdonald), pp. 7-10. IUCN, Gland.

van Heerden, J., Bainbridge, N., Burroughs, R.E.J. \& Kriek, N.P.J. (1989) Distemper-like disease and encephalitozoonosis in wild dogs (Lycaon pictus Temminck, 1820). Onderstepoort Journal of Veterinary Research, 48, 19-21.

van Heerden, J., Mills, M.G.L., Van Vuuren, M.J., Kelly, P.J. \& Dreyer, M.J. (1995) An investigation into the health status and diseases of wild dogs (Lycaon pictus) in the Kruger National Park. Journal of the South African Veterinary Medical Association, 66, 18-27.

Heinsohn, R. (1992) When conservation goes to the dogs. Trends in Ecology \& Evolution, 7, 214-215.

Hofmeyr, M., Bingham, J., Lane, E.P., Ide, A. \& Nel, L. (2000) Rabies in African wild dogs (Lycaon pictus) in the Madikwe Game Reserve, South Africa. Veterinary Record, 146, 50-52.

Kat, P.W., Alexander, K.A., Smith, J.S. \& Munson, L. (1995) Rabies and African wild dogs in Kenya. Proceedings of the Royal Society of London B, 262, 229-233.

Kohn, M.H. \& Wayne, R.K. (1997) Facts from faeces revisited. Trends in Ecology \& Evolution, 12, 223-227.

Laurenson, K., Esterhuysen, J., Stander, P. \& van Heerden, J. (1997) Aspects of rabies epidemiology in Tsumkwe District, Namibia. Onderstepoort Journal of Veterinary Research, 64, 39-45.

Lelo, S. (1990) Conservation status of the wild dog (Lycaon pictus) in the Serengeti ecosystem. In Serengeti Wildlife Research Centre Biennial Report 1988-89 (eds S.A. Huish and 
K.L.I. Campbell), pp. 27-30. Serengeti Wildlife Research Centre, Arusha, Tanzania.

Macdonald, D.W., Artois, M., Aubert, M., Bishop, D.L., Ginsberg, J.R., King, A., Kock, N. \& Perry, B.D. (1992) Cause of wild dog deaths. Nature, 360, 633-634.

McCormick, A.E. (1983) Canine distemper in African hunting dogs (Lycaon pictus) - possibly vaccine induced. Journal of $Z o 0$ Animal Medicine, 14, 66-71.

McLean, R.G. (1975) Raccoon rabies. In The Natural History of Rabies (ed. G.M. Baer), Vol. 2. Academic Press, New York.

Morell, V. (1995) Dogfight erupts over animal studies in the Serengeti. Science, 270, 1302-1303.

Ratanarapee, S., Wasi, C., Chavanich, L., Puthavathana, P., Chattuchai, K. \& Thongcharoen, P. (1982) Nonfatal rabies in dogs and other mammals. Is it usual? Journal of the Medical Association of Thailand, 65, 33-37.

Said, M.Y., Chunge, R.N., Craig, G.C., Thouless, C.R., Barnes, R.F.W. \& Dublin, H.T. (1995) African Elephant Database. IUCN/SSC, Gland.

Scheepers, J.L. \& Venzke, K.A.E. (1995) Attempts to reintroduce African wild dogs Lycaon pictus into Etosha National Park, Namibia. South African Journal of Wildlife Research, 25, 138-140.

Scott, J. (1991) Painted Wolves: Wild Dogs of the Serengeti-Mara. Hamish Hamilton, London.

Smith, J.S., Fishbein, D.B., Rupprecht, C.E. \& Clark, K. (1991) Unexplained rabies in three immigrants in the United States A virological investigation. New England Journal of Medicine, 324, 205-211.

Soave, O.A. (1964) Reactivation of rabies virus in a guinea pig due to the stress of crowding. American Journal of Veterinary Research, 25, 268-269.

Soave, O.A., Johnson, H.N. \& Nakamura, K. (1961) Reactivation of rabies virus infection with adrenocorticotropic hormones. Science, 133, 1360-1361.

de Villiers, M.S., Meltzer, D.G.A., van Heerden, J., Mills, M.G.L., Richardson, P.R.K. \& van Jaarsveld, A.S. (1995)
Handling-induced stress and mortalities in African wild dogs (Lycaon pictus). Proceedings of the Royal Society of London, B 262, 215-220.

Visee, A.M. (1996) African Wild Dogs, Mkomazi Game Reserve, Tanzania - Veterinary Report. Unpublished report, George Adamson Wildlife Preservation Trust.

Woodroffe, R. (1997) The conservation implications of immobilizing, radio-collaring and vaccinating free-ranging wild dogs. In The African Wild Dog: Status Survey and Conservation Action Plan (eds R. Woodroffe, J.R. Ginsberg and D.W. Macdonald), pp. 124-138. IUCN, Gland.

Woodroffe, R. (1999) Managing disease risks to wild mammals. Animal Conservation, 2, 185-193.

Woodroffe, R. \& Ginsberg, J.R. (1999a) Conserving the African wild dog, Lycaon pictus. I. Diagnosing and treating causes of decline. Oryx, 33, 132-142.

Woodroffe, R. \& Ginsberg, J.R. (1999b) Conserving the African wild dog, Lycaon pictus. II. Is there a role for reintroduction? Oryx, 32, 143-151.

Woodroffe, R., Ginsberg, J.R. \& Macdonald, D.W. (1997) The African Wild Dog. Status Survey and Conservation Action Plan. IUCN, Gland.

\section{Biographical sketches}

Rosie Woodroffe is an assistant professor and conservation biologist in the Department of Wildlife, Fish and Conservation Biology at the University of California, Davis. She was the lead author and compiler of The African Wild Dog: Status Survey and Conservation Action Plan published by the IUCN/ SSC Canid Specialist Group, of which she is a member. Her research interests include the resolution of conflicts between people and wildlife, and the control of infectious disease in threatened species. 